\title{
Paramoeba pemaquidensis (Sarcomastigophora: Paramoebidae) infestation of the gills of coho salmon Oncorhynchus kisutch reared in sea water
}

\author{
Michael L. Kent ${ }^{1, *}$, T. K. Sawyer ${ }^{2}$, R. P. Hedrick ${ }^{3}$ \\ ${ }^{1}$ Battelle Marine Research Laboratory, 439 West Sequim Bay Rd, Sequim, Washington 98382, USA \\ ${ }^{2}$ Rescon Associates, Inc., Box 206, Turtle Cove, Royal Oak, Maryland 21662 , USA \\ ${ }^{3}$ Department of Medicine, School of Veterinary Medicine, University of California, Davis, California 95616, USA
}

\begin{abstract}
Gill disease associated with Paramoeba pemaquidensis Page 1970 (Sarcomastigophora: Paramoebidae) infestations was observed in coho salmon Oncorhynchus kisutch reared in sea water Fish reared in net pens in Washington and in land-based tanks in California were affected. Approximately $25 \%$ mortality was observed in the net pens in 1985, and the disease recurred in 1986 and 1987. Amoeba infesting the gill surfaces elicited prominent epithelial hyperplasia. Typical of Paramoeba spp., the parasite had a Feulgen positive parasome (Nebenkörper) adjacent to the nucleus and floating and transitional forms had digitiform pseudopodia. We have established cultures of the organism from coho gills; it grows rapidly on Malt-yeast extract sea water medium supplemented with Klebsiella bacteria Ultrastructural characteristics and nuclear, parasome and overall size of the organism in study indicated it is most closely related to the free-living paramoeba $P$. pemaquidensis. The plasmalemma of the amoeba from coho gills has surface filaments. Measurements (in $\mu \mathrm{m}$ ) of the amoeba under various conditions are as follows: transitional forms directly from gills 28 (24 to 30), locomotive forms from liquid culture $21 \times 17$ (15 to $35 \times 11$ to 25 ), and locomotive forms from agar culture $25 \times 20$ (15 to $38 \times 15$ to 25). Nuclei and parasomes from liquid cultures were 5 to 7 and 3 to $5 \times 2$ to 3 , respectively. The disease was not induced by laboratory exposure of coho salmon to amoeba cultures, but the amoeba was consistently isolated from exposed fish and aquarium detritus for 4 wk after exposure. This suggests that the organism is an opportunistic pathogen which only proliferates on fish gills and causes disease under certain situations yet to be clearly defined. In vitro studies indicated that the optimal salinity for growth of the amoeba was between 15 and $20 \mathrm{ppt}$, while growth was greatly diminished below $10 \mathrm{ppt}$. This concurs with field observations where the amoeba was eradicated from fish held in sea water tanks following a reduction in salinity.
\end{abstract}

\section{INTRODUCTION}

Commercial rearing of salmonid fishes in sea water is an important and growing industry in several locations throughout the world. Research on diseases of salmonids has emphasized those occurring during their freshwater development, but with the increase in sea water aquaculture several new protozoan pathogens of salmonids reared in sea water have recently been identified (Hoffman 1984, Harrell \& Scott 1985, Harrell et al. 1985, Elston et al. 1987, Munday et al. 1988).

\footnotetext{
- Present address: Department of Fisheries and Oceans, Pacific Biological Station, Nanaimo, B.C., Canada V9R 5K6

Amoebic gill disease has affected several fishes reared in freshwater (Kubota \& Kamata 1971, Sawyer et al. 1974, 1975, Salas 1981, Daoust \& Ferguson 1985 , Nash et al. 1988), but few cases have been reported in marine fishes. Chatton $(1909,1910)$ reported gill disease associated with a vahlkampfid amoeba in Symphodus melops and $S$. tinca (Labridae) and proposed that this was a temporary infection by an otherwise free-living organism. Recently, Munday et al. (1988) described severe gill disease associated with a Paramoeba-like organism in seawater-reared Atlantic salmon Salmo salar and rainbow trout Salmo gairdneri in Tasmania. We have seen similar gill infestations in coho salmon Oncorhynchus kisutch reared in sea water and described here are the morphology, culture 
characteristics, infectivity, and associated pathology of Paramoeba pemaquidensis from epizootics in Washington and California, USA.

\section{MATERIALS AND METHODS}

Infested coho salmon Oncorhynchus kisutch from a net pen facility in Washington state were examined several times in 1985 to 1987 and coho reared in landbased seawater tanks in California were examined in April through June 1987. Wet mount preparations were examined by Nomarski phase interference microscopy. Gills and visceral organs were fixed in Davidson's solution (Humason 1979), processed for histological examination and stained with either hematoxylin and eosin or Feulgen stain for DNA. Gill tissue for electron microscopy was fixed and processed as described by Harrell et al. (1986). Amoebae from agar cultures were prepared for electron microscopy by fixing amoebae in $1: 15 \%$ glutaraldehyde with $0.1 \mathrm{M}$ cacodylate buffer and filtered sea water at 30 ppt.

In vitro culture. Amoebae from the Washington epizootic in 1987 were initially established in culture by placing gill tissue from infested coho salmon in $75 \mathrm{~cm}^{2}$ plastic tissue culture flasks with ca $25 \mathrm{ml}$ culture medium. The medium consisted of Medium 199 (Sigma, St. Louis, Mo., USA), filtered sea water at 25 ppt, $10 \%$ fetal calf serum, $5 \%$ chicken serum, and $100 \mu \mathrm{g} \mathrm{ml}^{-1}$ of the following antimicrobial compounds: neomycin, kanamycin, novobiocin, penicillin, streptomycin and nystatin.

Agar cultures were established from liquid cultures which had been passed ca 8 times. Malt-yeast-sea water (MYS) agar was prepared as described by Page (1983) and the surface of the agar was covered with a thin smear of Klebsiella bacteria prior to incubation. Cultures were maintained at $15^{\circ} \mathrm{C}$ unless otherwise indicated. This medium was routinely used for maintaining amoebae, and MYS agar was also prepared with sea water diluted to $5,10,15$ and $20 \mathrm{ppt}$ to investigate growth at reduced salinities.

Amoebae did not grow on MYS medium made at a salinity of 5 ppt and growth of the amoebae at 6 to 30 ppt was quantitated with the following method. Amoebae were transferred to Lab-Tek ${ }^{\circledR}$ Flaskettes ${ }^{(B)}$ (Miles Scientific, Naperville, Ill., USA) in $6 \mathrm{ml}$ sea water adjusted to the appropriate salinity. Initial concentration of the amoeba was $1.3 \times 10^{3} \mathrm{ml}^{-1}$. Amoebae were counted after $96 \mathrm{~h}$ with the aid of an inverted compound microscope. Klebsiella bacteria at $1 \times 10^{6}$ $\mathrm{ml}^{-1}$ were provided as food for the amoebae in each flaskette. Growth at temperatures from 5 to $20^{\circ} \mathrm{C}$ was investigated using the same system, and salinities in these cultures were maintained at $25 \mathrm{ppt}$.
Transmission. To determine the infectivity of the Paramoeba, coho salmon (mean wt $15 \mathrm{~g}$ ) were exposed to a moebae from agar cultures which had been passed 12 to 15 times. To ensure that they had not been previously exposed to the amoeba, the fish were obtained from a freshwater hatchery and acclimated to sea water in $200 \mathrm{l}$ aquaria for $2 \mathrm{~d}$ prior to exposure at the Battelle Marine Research Laboratory, Sequim, Washington. The fish were maintained in open systems, and the affluent water was sand-filtered. Water temperature was 9 to $11^{\circ} \mathrm{C}$ and salinity $30 \mathrm{ppt}$ throughout the experiment.

Amoebae were harvested from the agar cultures by washing with sterile sea water. Twenty fish were exposed to 300 amoebae $\mathrm{ml}^{-1}$ in a $20 \mathrm{l}$ static bath for 45 min. The affluent water was then turned on to fill the tank, and the flow maintained at $21 \mathrm{~min}^{-1}$. Fish were fed daily with a commercial pellet diet and detritus was allowed to accumulate at the aquarium bottom. Control fish were treated similarly, except they were not exposed to amoeba cultures.

Five fish samples were examined at 7, 14, 23 and $29 \mathrm{~d}$ post exposure (PI). Gills from all fish were examined in. wet mounts and histological sections. Gill tissue and detritus from the aquaria were cultured for amoebae on MYS agar as described above at 14,23 and 29 days PI.

\section{RESULTS}

\section{Pathology and treatment}

Significant mortalities at the Washington site were associated with the amoeba in the fall of 1985. Epizootics occurred again in fall 1986 and 1987, but mortalities were fewer and usually only small, emaciated fish were heavily infested. Moribund fish were lethargic and often accumulated at the surface or corners of the pens. The water temperature at this site typically ranges from 9 to $12^{\circ} \mathrm{C}$ during the fall. In contrast, the disease was first noted in the spring of 1987 at the California site, where the water temperature in the tanks was ca $13^{\circ} \mathrm{C}$.

Histological changes in the gills were consistent at both sites and severity of lesions were in concurrence with density of amoebae. The gills exhibited prominent epithelial hyperplasia which often resulted in complete fusion of the secondary lamellae (Fig. 1). Fusion of the distal portion of secondary lamellae resulted in the formation of large interlammelar vesicles. Amoebae were usually confined to the gill surface and rarely penetrated through the epithelium. No histopathological changes in visceral organs were associated with amoeba infestations. Some fish at both locations were also infected with a microsporidium, presumably Loma 

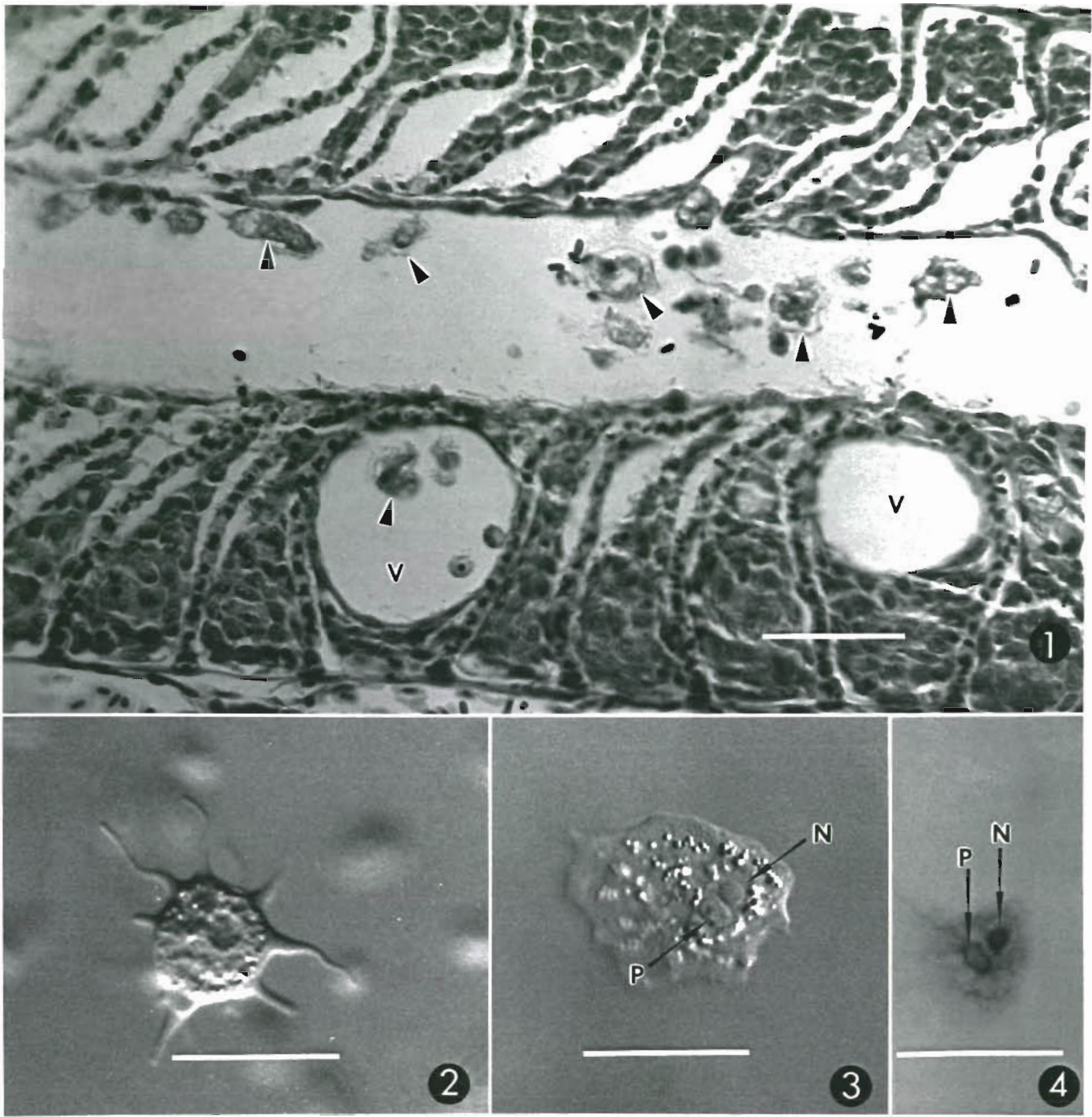

Figs. 1 to 4. Paramoeba pemaquidensis from the gills of coho salmon Oncorhynchus kisutch reared in sea water. Fig. 1 Epithelial hyperplasia, fusion of the secondary lamellae and interlamellar vesicles (V) associated with amoebae (arrows) infestation. H \& E. Bar $=50 \mu \mathrm{m}$. Fig. 2. Transitional form with digitiform pseudopodia from coho gill. Nomarski's phase contrast. Bar $=25 \mu \mathrm{m}$. Fig. 3. Locomotive form of Paramoeba from liquid culture. N: nucleus; P: parasome. Normarski's phase contrast. Bar $=25 \mu \mathrm{m}$. Fig. 4. Paramoeba from liquid culture. N: nucleus; P: parasome. Feulgen stain. Bar $=25 \mu m$

salmonae. In contrast to epithelial hyperplasia associated with the amoeba, the microsporidium formed xenomas and induced interstitial inflammation and vasculitis when the xenomas were ruptured and spores were dispersed throughout primary lamellae. Gill monogeneans Laminiscus strelkowi were observed on some affected fish in Washington in 1986 and 1987.

\section{Amoeba morphology}

Fresh wet mounts of the gills from fish at both location revealed numerous transitional forms with digitate pseudopodia (Fig. 2). A prominent parasome and vesicular nucleus was observed in amoebae which were allowed to adhere to glass (locomotive form) (Fig. 3). 

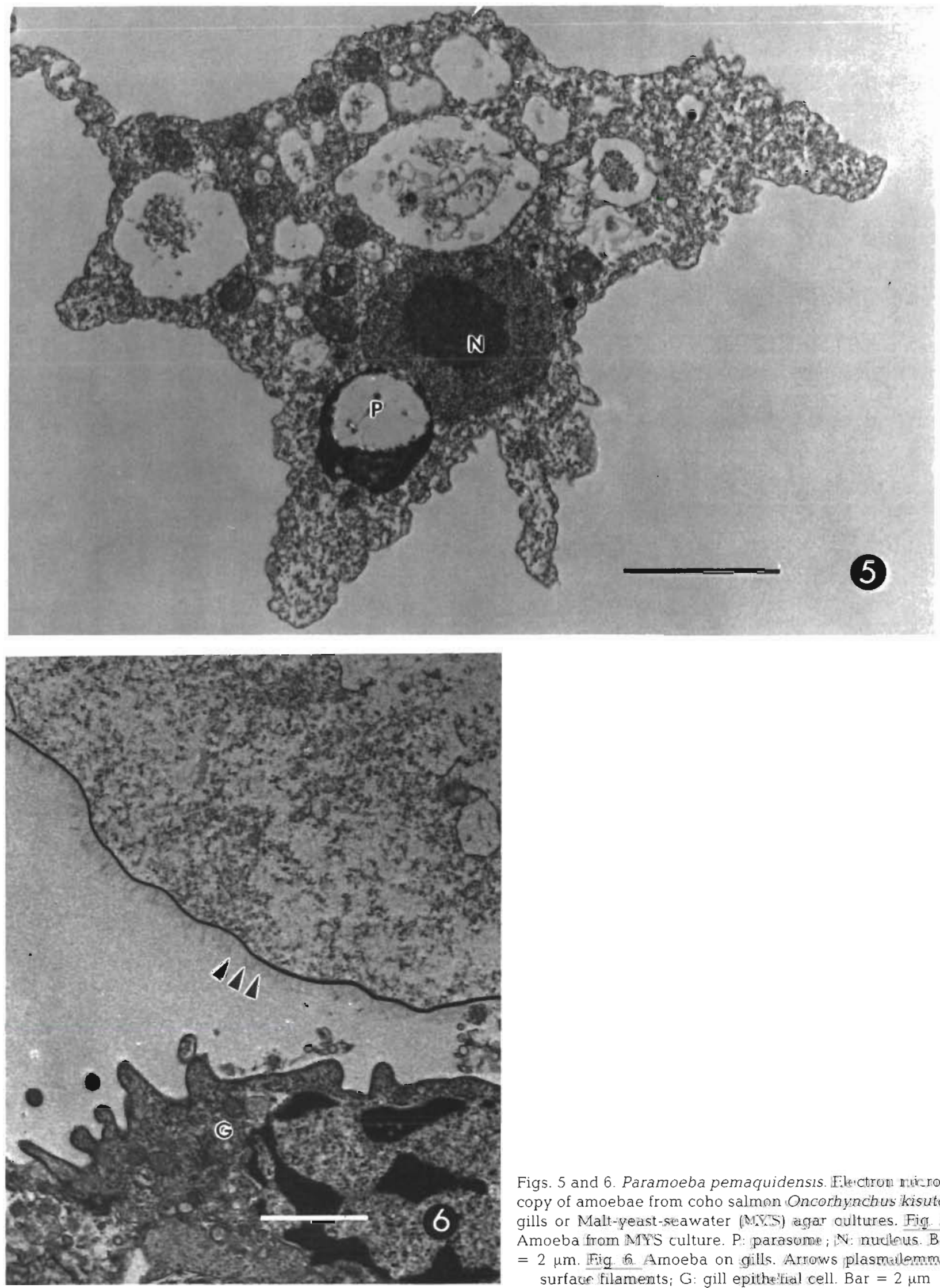

Figs. 5 and 6. Paramoeba pemaquidensis. Electron microscopy of amoebae from coho salmon Oncorhynchus kisutch gills or Malt-yeast-seawater (MYS) agar cultures. Fig. 5. Amoeba from MYS culture. P: parasome; N: nucleus. Bar $=2 \mu \mathrm{m}$. Fig. 6. Amoeba on gills. Arrows plasmalemmal surface filaments; G: gill epithelial cell. Bar $=2 \mu \mathrm{m}$ 
Gill sections and imprints also revealed a Feulgen positive parasome adjacent to the nucleus (Fig. 4). Most amoebae had only 1 parasome but occasionally 2 were observed. Measurements (in $\mu \mathrm{m}$ ) of 20 amoebae from wet mounts of infested gills, agar and liquid cultures are as follows: transitional forms from gills 28 (24 to 30 ), locomotive forms from liquid culture $21 \times 17$ (15 to $35 \times 11$ to 25 ), and locomotive forms from agar culture $25 \times 20(15$ to $38 \times 15$ to 25$)$. Nuclei and parasomes were measured from liquid cultures; nucleus 5 to $7_{1}$ parasome 3 to $5 \times 2$ to 3 .

Electron microscopy of amoebae on gill tissue and from agar culture (Fig. 5) revealed a parasome morphologically similar to those described previously (Perkins \& Castagna 1971, Cann \& Page 1982, Jones 1985). Adherent to the plasmalemma in amoeba from gills were numerous filaments which extended ca $350 \mathrm{~nm}$ from the surface (Fig. 6). These filaments were not detected in amoebae from agar cultures.

\section{In vitro growth characteristics}

Optimal growth occurred at ca $15 \mathrm{ppt}$ salinity, with little reduction from this maximum at 20 to $30 \mathrm{ppt}$ (Fig. 7). The amoeba grew and appeared morphologically intact at 8 to $9 \mathrm{ppt}$, but growth was slow and amoebae exhibited prominent cytoplasmic vacuoles. At 6 and 7 ppt most amoebae were rounded, vacuolated and growth was essentially absent. The amoeba grew slowly at $5{ }^{\circ} \mathrm{C}$ and growth was enhanced with increased temperature (Fig. 8).

\section{Transmission}

Paramoeba was isolated from the aquarium detritus and gills of all fish exposed to the amoeba at all sample dates when cultures were taken. However, no amoebae were observed on gills examined in wet mounts or histological sections of any exposed fish. One exposed fish exhibited mild, diffuse epithelial hyperplasia of the gills at $29 \mathrm{~d}$, but this was not associated with amoebae. Paramoeba was not isolated from the detritus or fish gills from the control aquarium, and no amoeba or gill lesions were observed in wet mount or histological preparations from these fish.

\section{DISCUSSION}

The presence of a parasome, vesicular nucleus, digitate pseudopodia, lack of cysts and marine habitat identify the amoeba in study as a member of the genus Paramoeba. Six Paramoeba spp. have been described;
$P$. aestuarina, $P$. eilhardi, $P$. schaudinni, $P$. pemaquidensis, $P$. perniciosa and $P$. invadens. $P$. perniciosa is an invasive pathogen in blue crabs (Sprague et al. 1969, Johnson 1977) and $P$. invadens infects sea urchins Strongylocentrotus droebachiensis (Jones 1985, Jones \& Scheibling 1985), whereas the remaining described species are free-living. The ultrastructure of the parasome and nucleus of the amoeba in study is similar to that described for other Paramoeba spp. (Perkins \& Castagana 1971, Cann \& Page 1982, Jones 1985), and the surface filaments are similar to those described on some strains of Paramoeba pemaquidensis (Cann \& Page 1982).

In addition to the presence of these surface filaments, the organism appears most closely related to Paramoeba pemaquidensis based on the ability to thrive on agar cultures, size of the parasome, nucleus and overall diameter, and length to width ratio (Page 1970, 1983,

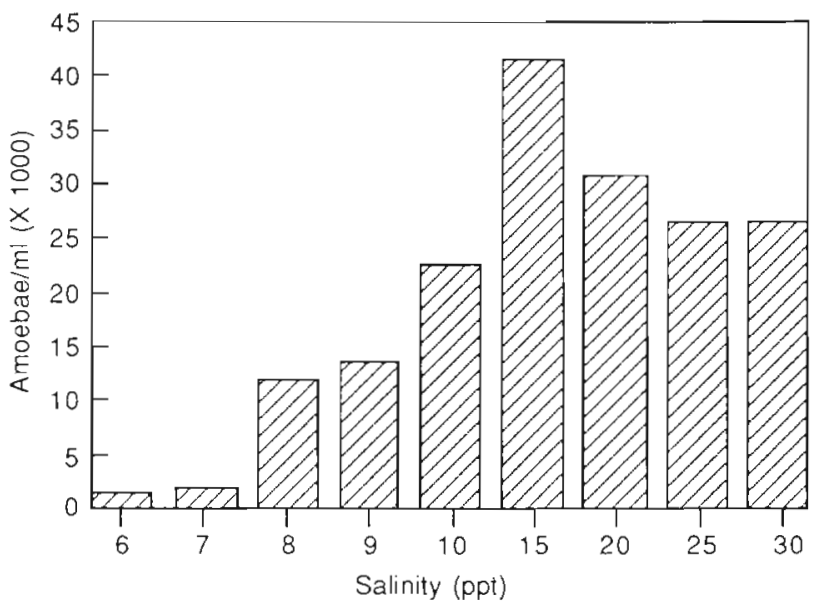

Fig. 7 Paramoeba pemaquidensis. Effects of salinity on growth in vitro for $96 \mathrm{~h}$

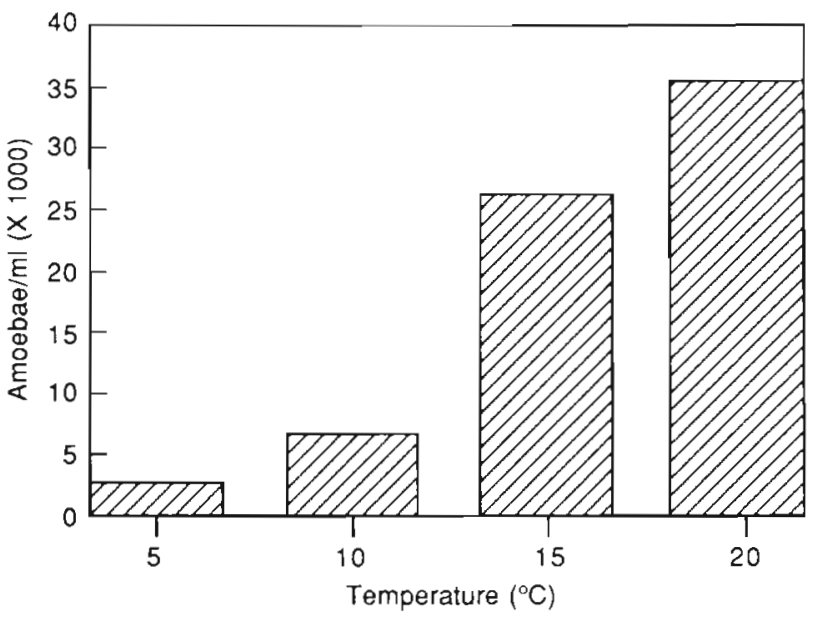

Fig. 8. Paramoeba pemaquidensis. Effects of temperature on growth in vitro for $96 \mathrm{~h}$ 
Bovee \& Sawyer 1979, Cann \& Page 1982). Nucleus, parasome and overall diameters of the strain in study are smaller than those of $P$. eilhardi and larger than those of $P$. aestuarina and $P$. perniciosa. Furthermore, the latter is an obligate parasite of the blue crab Callinectes sapidus and has not been maintained in vitro.

Paramoeba invadens is similar in size to our isolate, but lacks plasmalemmal hairs (Jones 1985). P. invadens also is quite similar in size and culture characteristics to other strains of $P$. pemaquidensis and the taxonomic distinction of these 2 species is unclear. Furthermore, the presence or absence of plasmalemmal surface filaments is not a sufficient criterion alone to differentiate these species because some strains of $P$. pemaquidensis lack these hairs and their presence may depend on culture characteristics. They were observed on some amoebae directly associated with gills (Fig. 6), whereas they were not detected on amoebae from agar cultures. Paramoeba spp. vary greatly in size dependent on culture conditions and density of infection (Sawyer 1969, Cann \& Page 1982) and further studies beyond morphological comparisons, such as isoenzyme analysis, are needed to clarify the taxonomic relationships of Paramoeba spp.

Along with the preliminary report by Munday et al. (1988), this is the first report of Paramoeba pemaquidensis from the Pacific Ocean and the first report of a Paramoeba infestation in a vertebrate. Amoebae have been associated with fish reared in freshwater, and the pathological response to infestations is typically hyperplasia of the branchial epithelium (Sawyer et al. 1975 , Daoust \& Ferguson 1985). The only reports of amoebic gill infestations in marine fishes that we are aware of are those by Chatton $(1909,1910)$ in Symphodus spp. (Labridae) and a Paramoeba-like amoeba from net pen-reared salmonids in Australia (Munday et al. 1988). We have examined histological material from infested salmon from Australia and the amoeba and associated disease appears identical to those of salmon in Washington and California.

The amoeba of our study exhibited poor growth in vitro at salinities less than $10 \mathrm{ppt}$ (Fig. 7). This concurs with in vitro observations; the amoeba and associated disease was eradicated from fish held in seawater tanks in California following a brief reduction in salinity, and Munday et al. (1988) reported that the Australian amoeba is eradicated by moving infested fish in pens to an area with a heavy freshwater influx. However, the precise salinity reduction needed to eradicate the infestation is yet to be determined.

Neither severe epithelial hyperplasia of the gills nor mortality was induced in the laboratory exposure study, which indicate that the amoeba was not pathogenic under the experimental conditions employed. The amoeba is likely an opportunistic pathogen which proliferates on fish gills and causes disease only under ceretain conditions which are yet to be precisely defined. This is similar to bacterial gill disease of freshwater salmonids. In this disease, certain bacterial epiphytes (Flavobacterium or Cytophaga spp.) are associated with gill hyperplasia, but the disease is difficult to reproduce with bacteria isolated from affected fish (Wakabayashi et al. 1980, Snieszko 1981). Based on our field observations, the water temperature during the exposure experiment appears to be at the low range for the occurrence of the disease, and in vitro growth of the amoeba is enhanced at higher temperatures (Fig. 8). Furthermore, Munday et al. (1988) reported most epizootics in Australia at temperatures greater than $17^{\circ} \mathrm{C}$. Also, it is possible that the amoeba attain 'bloom' populations when the water contains abundant food organisms that favor their growth. Repeated passage of the amoeba on artificial media prior to exposure to fish may have also diminished its virulence.

Another factor which may explain the lack of disease in experimentally exposed fish is that massive proliferation of the amoeba may only occur on gills with preexisting lesions, induced by such agents as other parasites, chemical or mechanical injury. Goldes et al. (1988) reported moderate to severe gijll infestations by the ectoparasitic flagellate IChtyobodo necator in rainbow trout exposed to high levels of inert suspended solids in the form of clay kaolin, whereas fish kept in otherwise identical conditions were not infested. Many coho salmon with prominent Paramoeba infestations in our study were also infected with a microsporidium (Loma salmonae) or a monogenean (Laminiscus strelkowl). However, the amoeba was the only pathogen detected in other salmon with severe epithelial hyperplasia from the same epizootics.

In agreement with B. L. Munday, Tasmania Institute of Technology, Tasmania (pers. comm.), we feel that the amoeba can be a primary pathogen and cause severe disease in seawater-reared salmon under certain conditions. In addition to clarification of taxonomic relationships of the amoeba from Australia, our isolate, and other strains of Paramoeba pemaquidensis and $P$. invadens, further studies are needed to elucidate host-parasite relationships of the disease (e.g. determination of more precise conditions under which the amoeba proliferates on gills and causes disease)

Acknowledgements. This work was supported by Battelle Memorial Institute, Corporate Technical Development Project Number B-0322-4051, Columbus, Ohio, and Domsea Farms, Inc. We thank Drs R. A. Elston and J. Groff for helpful suggestions, $M . T$ Wilkinson for histological preparations and $\mathrm{R}$. Munn for electron microscopy preparations. 


\section{LITERATURE CITED}

Bovee, E. C., Sawyer, T K. (1979). Marine flora and fauna of the Northeastern United States. Protozoa: Sarcodina: Amoebidae. NOAA Tech. Rep. Natl. Mar. Fish. Serv. Circular 419 , p. $1-56$

Cann, J. P., Page, F. C. (1982). Fine structure of small freeliving Paramoeba (Amoebida) and taxonomy of the genus. J. mar biol. Ass. U. K. 62: 25-43

Chatton, E. (1909). Une amibe, Amoeba mucicola. n. sp. parasite des branchies des labres, associée à une trichodine. C. r. Séanc. Soc. Biol. 67: 690-692

Chatton, E. (1910). Protozoaires parasites des branchies des labres, Ameoba mucicola, Chatton, Trichodina labrorum n. sp. Archs. Zool. exp. gen. 5: 239-266

Daoust, P.-Y., Ferguson, H. W. (1985). Nodular gill disease: a unique form of proliferative gill disease in rainbow trout, Salmo gairdnen Richardson. J. Fish Dis. 8: 511-522

Elston, R. A., Kent, M. L., Harrell, L. H. (1987). An intranuclear micorsporidium associated with acute anemia in the chinook salmon, Oncorhynchus tshawytscha. J. Protozool. 34: $274-277$

Goldes, S. A., Ferguson, H. W., Moccia, R. D., Daoust, P.-Y. (1988). Histological effects of the inert suspended clay kaolin on the gills of juvenile rainbow trout, Salmo gairdneri Richardson. J. Fish Dis. 11: 23-33

Harrell, L. W., Scott, T M. (1985), Kudoa thyrsitis (Gilchirst) (Myxosporea; Multivalvulida) in Atlantic salmon, Salmo salar L. J. Fish Dis, 8: 329-332

Harrell, L. W., Elston, R. A., Scott, T M., Wilkinson, M. T (1986). A significant new systemic disease of net-pen reared chinook salmon (Oncorhynchus tshawytscha) brood stock. Aquaculture 55: 249-262

Hoffman, G. L. (1984). Two fish pathogens, Parvicapsula sp. and Mitraspora cyprini Myxosporea, new to North America. Symp. Biol. Hung. 23: 127-135

Humason, G. L. (1979). Animal tissue techniques. W. H. Freeman, San Francisco

Johnson, P. T (1977). Paramoebiasis in the blue crab, Callinectes sapidus. J. Invert. Pathol. 29: 308-320

Jones, G. M. (1985). Paramoeba invadens n. sp. (Amoebida Paramoebidae), a pathogenic amoeba from the sea urchin, Strongylocentrotus droebachiensis, in Eastern Canada. J. Protozool. 32: 564-569
Jones, G. M., Scheibling, R. E. (1985). Paramoeba sp (Amoebida, Paramoebidae) as the possible causative agent of sea urchin mass mortality in Nova Scotia. J. Parasitol. 71: 559-565

Kubota, S., Kamata, T (1971). An amoeba observed on the gills of amago. Fish Pathol. (Japan) 5: 155

Munday, B. L., Lange, K., Foster, C., Lester, R., Handlinger, J. (1988). Amoebic gill disease in sea-caged salmonids in Tasmanian waters. Tasm. Fish. Res. (in press)

Nash, G., Nash, M., Schlotfeldt, H.-J. (1988). Systemic amoebiasis in cultured European catfish, Silurus glanis L. J. Fish Dis. 11: 57-71

Page, F. C. (1970). Two new species of Paramoeba from Maine. J. Protozool. 17: 421-427

Page, F. C. (1983). Marine Gymnamoebae. Inst. Terrestrial Ecol., Cambridge, UK

Perkins, F. O., Castagana, M. (1971). Ultrastructure of the Nebenkorper or 'secondary nucleus' of the parasitic amoeba Paramoeba perniciosa (Amoebida, Paramoebidae). J. Invert. Pathol. 17: 186-193

Salas, E. C. M. (1981). Sarcodinos de peces e invertebrados acuaticos. Bol. Lima 15: 3-11

Sawyer, T K. (1969). Preliminary study on the epizootiology and host-parasite relationship of Paramoeba sp. in the blue crab, Callinectes sapidus. Proc. natl Shellfish. Ass. 59: $60-64$

Sawyer, T. K., Hnath, J. G., Conrad, J. F. (1974). Thecamoeba hoffmanisp. n. (Amoebida: Thecamoebidae) from the gills of fingerling salmonid fish. J. Parasitol. 60:677-682

Sawyer, T K., Hoffman, G. L., Hnath, J. G., Conrad, J. F. (1975). Infection of salmonid fish gills by aquatic amebas (Amoebida: Thecamoebidae). In: Ribelin, W. E., Migaki, G. (eds.) The pathology of fishes. University of Wisconsin Press, Madison, p. 143-150

Snieszko, S. F. (1981). Bacterial gill disease of freshwater fishes. Fish Disease Leaflet 62, U.S. Fish Wildl. Serv., Kearnysville, West Virginia, USA, p. 1-11

Sprague, V., Beckett, R. L., Sawyer, T K. (1969). A new species of Paramoeba (Amoebida, Paramoebidae) parasitic in the crab Callinectes sapidus. J. Invert, Pathol. 2: $167-174$

Wakabayashi, H., Egusa, S., Fryer, J. L. (1980). Characteristics of filamentous bacteria isolated from a gill disease of salmonids. Can. J. Fish. Aquat. Sci. 37: 1499-1504 